Pacific Journal of Mathematics

ON THE BEHAVIOR OF A CAPILLARY SURFACE AT A 


\title{
ON THE BEHAVIOR OF A CAPILLARY SURFACE AT A RE-ENTRANT CORNER
}

\author{
Nicholas J. KoREvaAR
}

\begin{abstract}
Changes in a domain's geometry can force striking changes in the capillary surface lying above it. Concus and Finn [1] first studied capillary surfaces above domains with corners, in the presence of gravity. Above a corner with interior angle $\theta$ satisfying $\theta<\pi-2 \gamma$, they showed that a capillary surface making contact angle $\gamma$ with the bounding wall must approach infinity as the vertex is approached. In contrast, they showed that for $\theta \geqq \pi-2 \gamma$ the solution $u(x, y)$ is bounded, uniformly in $\theta$ as the corner is closed. Since their paper appeared, the continuity of $u$ at the vertex has been an open problem in the bounded case. In this note we show by example that for any $\theta>\pi$ and any $\gamma \neq \pi / 2$ there are domains for which $u$ does not extend continuously to the vertex. This is in contrast to the case $\pi>\theta>\pi-2 \gamma$; here independent results of Simon [5] show that $u$ actually must extend to be $C^{1}$ at the vertex.
\end{abstract}

We consider bounded domains $\Omega$ in $\boldsymbol{R}^{2}$ with piecewise smooth boundaries $\partial \Omega$, and functions $u(x, y)$ satisfying

(i ) $\operatorname{div} T u=2 H(u)=\kappa u$ in $\Omega ; T u=D u / \sqrt{1+D u^{2}}, H(u)=$ mean curvature of the surface $z=u(x, y), \kappa>0$.

(ii) $T u \cdot n=\cos \gamma$ on the smooth part of $\partial \Omega ; 0 \leqq \gamma \leqq \pi, n=$ exterior normal to $\partial \Omega$.

Physically $u$ describes the capillary surface formed when a vertical cylinder with horizontal cross section $\Omega$ is placed in an infinite reservoir of liquid having rest height $z=0$. Then

$$
\kappa=\frac{\rho g}{\sigma},
$$

where

$$
\begin{aligned}
& \rho=\text { density of liquid } \\
& g=\text { (downward) acceleration of gravity } \\
& \sigma=\text { surface tension between liquid and air. }
\end{aligned}
$$

$$
\cos \gamma=\frac{\sigma_{1}}{\sigma}
$$

where

$$
\sigma_{1}=\text { surface attraction between liquid and cylinder. }
$$

Geometrically $\gamma$ is the contact angle between the capillary surface and the bounding cylinder; it is the angle between the downward 
normal of the surface $z=u(x, y)$, and the exterior normal of the cylinder $\partial \Omega \times \boldsymbol{R}$.

If $\gamma=\pi / 2$, the only solution to (i) and (ii) is $u \equiv 0$. If $\gamma \neq \pi / 2$, by considering either $u$ or $-u$, we make the usual assumption that $0 \leqq \gamma<\pi / 2$. This is the case in which the surface rises to meet the cylinder, or "wets" it.

Let $\theta$ and $\gamma$ satisfy

$$
\pi<\theta \leqq 2 \pi, \quad 0<\gamma<\pi / 2 .
$$

We will construct a domain for which a bounded solution $u$ to (i) and (ii) exists, but having a corner of interior angle $\theta$ at which there is a jump discontinuity in $u$. (The arguments can be modified to include the case $\gamma=0$.)

Determine the domain scale by fixing $R>0$ (Fig. 1). Since $\theta>\pi$, we can pick $\theta_{1}$ and $\theta_{2}$, satisfying

$$
\theta_{1}>\pi-\gamma, \quad \pi>\theta_{2}>\gamma, \quad \theta_{1}+\theta_{2}=\theta .
$$

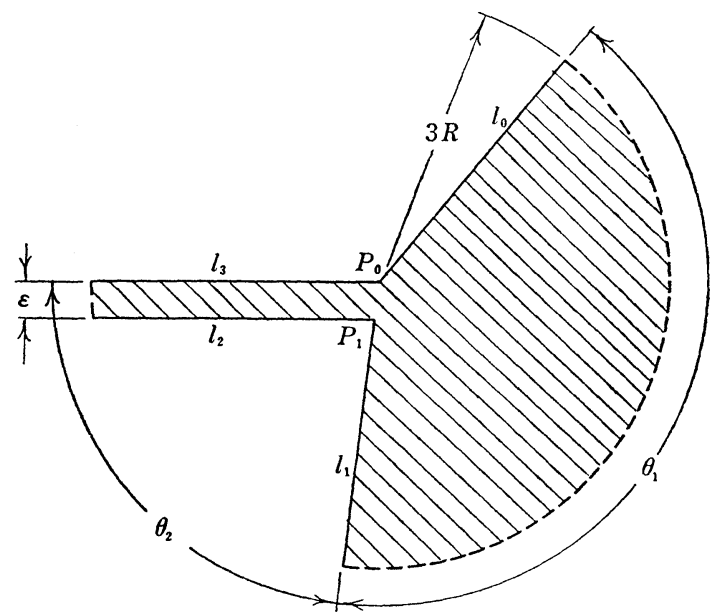

Figure 1. The intersection of $\Omega_{\varepsilon}$ with the disc of radius $3 R$

$$
\begin{array}{lll}
\theta_{1}>\pi-\gamma & P_{0}=(0,0) & l_{0}=\{y \cos \theta=x \sin \theta\} \\
\pi>\theta_{2}>\gamma & P_{1}=\left(-\varepsilon \cot \theta_{2},-\varepsilon\right) & l_{1}=\left\{y \cos \theta_{2}=x \sin \theta_{2}\right\} \\
\theta_{1}+\theta_{2}=\theta>\pi & & l_{2}=\{y=-\varepsilon\} \\
& & l_{3}=x \text {-axis }
\end{array}
$$

For positive $\varepsilon$ less than $R \sin \theta_{2}$, let $\Omega_{\varepsilon}$ be a bounded domain, of which the intersection with $B_{3 R}(0)$ is shown in Fig. 1, and which has $C^{4}$ boundary except at $P_{0}$ and $P_{1} . \quad\left(B_{3 R}(0)\right.$ is the disc of radius $3 R$ centered at the origin.)

LEMMA 1. There exists a unique solution to (i) and (ii) in any $\Omega_{\varepsilon}$. It is bounded above and nonnegative. 
Proof. Because $\Omega_{\varepsilon}$ is $C^{2}$, except for a finite number of re-entrant corners, it satisfies a uniform internal sphere condition with contact angle $\gamma$, for any $\gamma$. Therefore it is admissible in the sense of Finn and Gerhardt [4]. Thus there is a bounded, nonnegative, real analytic function $u_{\varepsilon}(x, y)$ in $\Omega_{\varepsilon}$, satisfying (i). Because $u$ is energy minimizing in the sense of Emmer [3], the regularity theory of Simon and Spruck [6] implies that everywhere the boundary is $C^{4}, u_{\varepsilon}$ extends to be at least $C^{2}$, and satisfies (ii). Uniqueness follows from a maximum principle of Concus and Finn [2].

We are interested in the behavior of $u_{\varepsilon}$ near $P_{0}$, as $\varepsilon$ approaches 0 . Lemma 2 will show that $u_{\varepsilon}$ stays uniformly bounded in one sector near $P_{0}$, and Lemma 3 show that in another sector it gets uniformly large. It follows that $u_{\varepsilon}$ eventually has a jump discontinuity at $P_{0}$. Let $I_{\varepsilon}$ be the subdomain of $\Omega_{\varepsilon}$ shown in Fig. 2 . Then we have

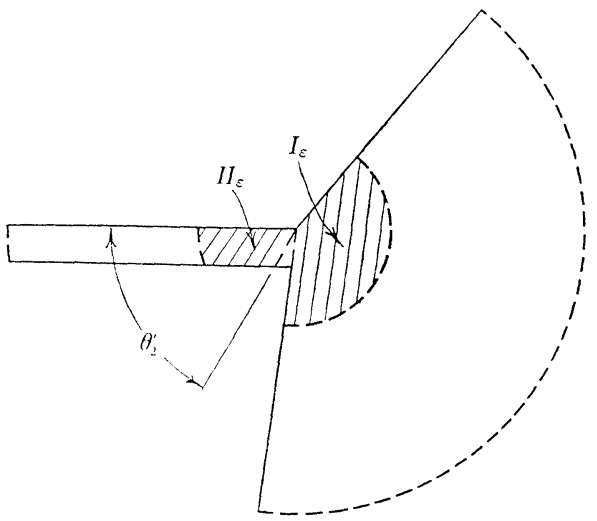

FIGURE 2. The subdomains $I_{\varepsilon}$ and $I I_{\varepsilon}$

$$
\begin{aligned}
\theta_{2}>\theta_{2}^{\prime}>\gamma \quad B_{R}(0) & =\left\{x^{2}+y^{2}<R^{2}\right\} \\
I_{\varepsilon} & =B_{R}(0) \cap\{y \cos \theta>x \sin \theta\} \cap\left\{y \cos \theta_{2}<x \sin \theta_{2}\right\} \\
I I_{\varepsilon} & =B_{R}(0) \cap\{y<0\} \cap\{y>-\varepsilon\} \cap\left\{y \cos \theta_{2}^{\prime}>x \sin \theta_{2}^{\prime}\right\}
\end{aligned}
$$

LeMma 2. $u_{s}$ is uniformly bounded in $I_{\varepsilon}$, independently of $\varepsilon$.

Proof. In this and the following lemma the basic tool is a comparison method of Concus and Finn [2] for surfaces of known mean curvature and contact angle.

Consider circles of radius $R$ which either lie entirely in $\Omega_{\varepsilon}$ or contact $\partial \Omega_{\varepsilon}$ only at a point of tangency. (In particular, do not allow them to have contact at $P_{0}$ or $P_{1}$.) If $\theta_{1}<\pi$, also allow circles which intersect $\partial \Omega_{\varepsilon}$ at two points on $l_{0}-P_{0}$, making an angle of no more than $\pi-\theta_{1}$ with $l_{0}$ at these intersections. Every point in $I_{\varepsilon}$ lies interior to at least one of these circles (see Fig. 3). 


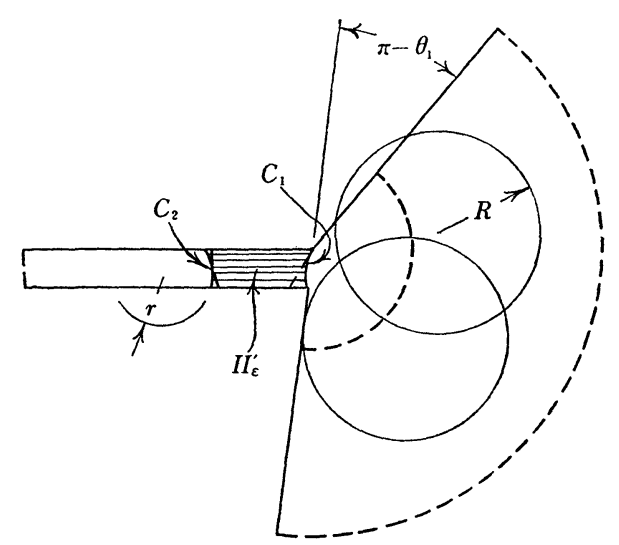

Figure 3. Equatorial circles near $I_{\varepsilon}$

The region $I I_{\varepsilon}^{\prime}$ above which $v$ is defined.

In $\boldsymbol{R}^{3}$ consider a closed lower hemisphere $L$ with equatorial circle $E$, so that the projection $\pi(E)$ of $E$ onto $R^{2}$ is one of the above circles (see Fig. 4). If $L$ contacts $l_{0} \times \boldsymbol{R}$, then along the arc of intersection $A$ the contact angle $\gamma_{L}$ equals the angle between $\pi(E)$ and $l_{0}$. Thus $\gamma_{L} \leqq \pi-\theta_{1}<\gamma$. Because $P_{0}$ and $P_{1}$ are the only two boundary points at which $u_{\varepsilon}$ may not be $C^{2}, u_{\varepsilon}$ is $C^{2}$ on $\overline{\pi(L) \cap \Omega_{\varepsilon}}$.

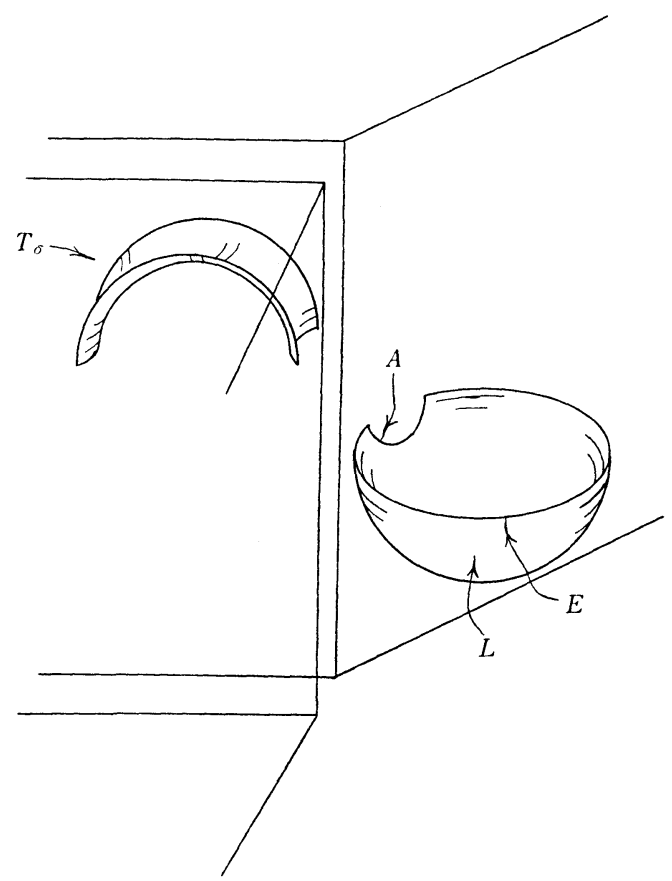

Figure 4. A lower hemisphere $L$ contacting $\partial \Omega_{\varepsilon} \times \boldsymbol{R}$ along $A$, with contact angle less than $\gamma$. The "undeside" $T_{\delta}$ of a torus, contacting $\partial \Omega_{\varepsilon} \times \boldsymbol{R}$ with contact angle greater than $\gamma$. 
Raise $L$ until it lies above the bounded surface $\left\{z=u_{\varepsilon}(x, y)\right\}$. Lower $L$ until the two surfaces first contact each other. Let $Q_{0}=$ $\left(x_{0}, y_{0}, u_{\varepsilon}\left(x_{0}, y_{0}\right)\right)$ be a point of first contact.

$Q_{0}$ is not on $E$. This is because $L$ is vertical along $E$ whereas $u_{\varepsilon}$ is $C^{2}$.

$Q_{0}$ is not on $A$ : The end points of $A$ are on $E$ and are already excluded. If $Q_{0}$ was not an end point, the traces of the two surfaces on $l_{0} \times \boldsymbol{R}$ would be tangent there. Since $L$ contacts $l_{0} \times \boldsymbol{R}$ at a steeper angle than the capillary surface, it would follow that $L$ was actually below the surface in the interior normal direction from $Q_{0}$. Thus $Q_{0}$ would not be a point of first contact.

Thus $\left(x_{0}, y_{0}\right)$ lies in the interior of $\pi(L) \cap \Omega_{\varepsilon}$. Since $Q_{0}$ is an interior point of first contact, the two surfaces are tangent there, and since $L$ is nowhere below $\left\{z=u_{\varepsilon}(x, y)\right\}$, it follows that

$$
H\left(u_{\varepsilon}\right)\left(x_{0}, y_{0}\right) \leqq \frac{1}{R} \quad\left(\text { since } \frac{1}{R} \text { is the mean curvature of } L\right) \text {. }
$$

Using (i) gives:

$$
u_{\varepsilon}\left(x_{0}, y_{0}\right) \leqq \frac{2}{\kappa R}
$$

Since $L$ varies in height by $R$,

$$
u_{\varepsilon}(x, y) \leqq \frac{2}{\kappa R}+R \text { for all }(x, y) \in \pi(L) \cap \Omega_{\varepsilon} .
$$

By our previous comments this estimate holds in all of $I_{\varepsilon}$.

Fix $\theta_{2}^{\prime}$ with $\gamma<\theta_{2}^{\prime}<\theta_{2}$ and let $I I_{\varepsilon}$ be the subregion of $\Omega_{\varepsilon}$ as described in Fig. 2. Then we have

LEMMA 3. $u_{\varepsilon}(x, y)$ approaches $\infty$ uniformly in $I I_{\varepsilon}$, as $\varepsilon$ approaches 0 .

Proof. Consider the unique circle $C_{1}$, containing $P_{0}$, making an angle $\theta_{2}^{\prime}$ with $l_{3}$ and going through $P_{1}$ if $\theta_{2} \leqq \pi / 2$, or through $(0,-\varepsilon)$ if $\theta_{2}>\pi / 2$. Let $C_{2}$ be a circle of the same radius translated $2 R$ units to the left.

There is a unique torus in $\boldsymbol{R}^{3}$ containing $C_{1}$ and $C_{2}$. It is generated by rotating $C_{1}$ about an axis parallel to the $y$-axis and going through $Q_{1}$, the point midway between $C_{1}$ and $C_{2}$. Let $I I_{\varepsilon}^{\prime}$ be the part of $\bar{\Omega}_{\varepsilon}$ on or to the left of $C_{1}$, and on or to the right of $C_{2}$ (see Fig. 3). Then in $I I_{\varepsilon}^{\prime}$, the "underside" $T$ of the torus is given by

$$
v(x, y)=\left[\left(R-\sqrt{r^{2}-\left(y-y_{1}\right)^{2}}\right)^{2}-\left(x-x_{1}\right)^{2}\right]^{1 / 2},
$$


where $\left(x_{1}, y_{1}\right)=Q_{1}$ (see Fig. 4$) . \quad T$ contacts $l_{3} \times \boldsymbol{R}$ with contact angle $\theta_{2}^{\prime}>\gamma$, and contacts $l_{2} \times \boldsymbol{R}$ with contact angle of at least $\theta_{2}^{\prime}$. It is vertical at $C_{1}$ and $C_{2}$.

Let any $\delta>0$ be given. In order to avoid $P_{0}$ and $P_{1}$ translate $T \delta$ units to the left and call it $T_{\delta}$, as in Fig. 4 . Lower $T_{\delta}$ beneath $\left\{z=u_{\varepsilon}(x, y)\right\}$, and raise it until the first contact is made. By reasoning as in Lemma 2 it follows that if $\left(x_{0}, y_{0}, u_{\varepsilon}\left(x_{0}, y_{0}\right)\right)$ is a point of first contact, then it does not occur on the boundary of $T_{\delta}$. Thus it is a point of tangency and since $T_{\delta}$ is nowhere above $\left\{z=u_{\varepsilon}(x, y)\right\}$, the mean curvature of $T_{\delta}$ is no bigger than that of $u_{\varepsilon}$ at $\left(x_{0}, y_{0}, u_{\varepsilon}\left(x_{0}, y_{0}\right)\right)$. But by looking at the normal curvatures for a torus, one can calculate the following inequality:

$$
H(v)(x, y) \geqq \frac{1}{2}\left(\frac{1}{r}-\frac{1}{R-r}\right) \quad(x, y) \in I I_{s}^{\prime}
$$

so that

$$
\operatorname{div} T u_{\varepsilon}\left(x_{0}, y_{0}\right) \geqq\left(\frac{1}{r}-\frac{1}{R-r}\right)
$$

or

$$
u_{\varepsilon}\left(x_{0}, y_{0}\right) \geqq \frac{1}{\kappa}\left(\frac{1}{r}-\frac{1}{R-r}\right) .
$$

Since $T_{\delta}$ varies in height by at most $R$, and since $\delta$ can be chosen arbitrarily small,

$$
u_{\varepsilon}(x, y) \geqq \frac{1}{\kappa}\left(\frac{1}{r}-\frac{1}{R-r}\right)-R \text { for }(x, y) \text { in } I I_{\varepsilon}^{\prime} .
$$

Since $I I_{\varepsilon} \subset I I_{\varepsilon}^{\prime}$ for $\varepsilon$ small enough, the last inequality eventually holds in $I I_{\varepsilon}$. Noticing that $r$ is proportional to $\varepsilon$ and $R$ is fixed, the result follows.

Combining the three lemmas yields the desired result:

Theorem. For $\varepsilon$ sufficiently small, the solution $u_{\varepsilon}(x, y)$ to the capillary problem (i) and (ii) in $\Omega_{\varepsilon}$ cannot be extended continuously to the vertex of the re-entrant corner of angle $\theta$.

Although this theorem shows that $u_{\varepsilon}$ need not extend nicely to the vertex, simple experiments with glass slides placed vertically in water indicate that the capillary surface itself still extends in a regular fashion to its boundary. 


\section{REFERENCES}

1. P. Concus and R. Finn, On the behavior of a capillary surface in a wedge, Proc. Nat. Acad. Sci., 63 (1.969), 292-299.

2. - On capillary free surfaces in a gravitational field, Acta Math., 132 (1974), 207-223.

3. M. Emmer, Esistenzá, unicitá e regolarità nelle superfici di equilibrio nei capillari, Ann. Univ. Ferrara Sez VII, 18 (1973), 79-94.

4. R. Finn and C. Gerhardt, The internal sphere condition and the capillarity problem, Ann. Mat. Pura Appl. IV, 112 (1977), 13-31.

5. L. Simon, Regularity of capillary surfaces over domains with corners, (to appear in Pacific J. Math.).

6. L. Simon and J. Spruck, Existence and regularty of a capillary surface with prescribed contact angle, Arch. Rational Mech. Anal., 61 (1976), 19-34.

Received November 16, 1979.

STANFORD UNIVERSITY

Stanford, CA 94305 



\section{PACIFIC JOURNAL OF MATHEMATICS}

\section{EDITORS}

DONALD BABBITT (Managing Editor)

University of California

Los Angeles, CA 90024

Hugo Rossi

University of Utah

Salt Lake City, UT 84112

C. C. MOORE and ANDREW OGG

University of California

Berkeley, CA 94720
J. DUGUNDJI

Department of Mathematics

University of Southern California

Los Angeles, CA 90007

R. FinN and J. Milgram

Stanford University

Stanford, CA 94305

\section{ASSOCIATE EDITORS}
E. F. BECKENBACH
B. H. NeumanN
F. WOLF
K. YoSHIDA

\section{SUPPORTING INSTITUTIONS}

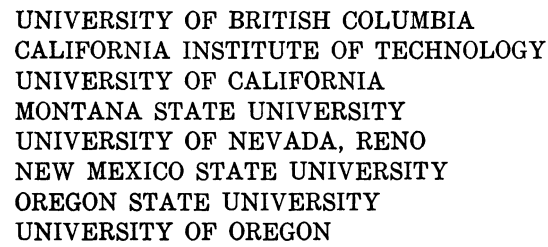

UNIVERSITY OF BRITISH COLUMBIA CALIFORNIA INSTITUTE OF TECHNOLOGY UNIVERSITY OF CALIFORNIA MONTANA STATE UNIVERSITY UNIVERSITY OF NEVADA, RENO NEW MEXICO STATE UNIVERSITY OREGON STATE UNIVERSITY UNIVERSITY OF OREGON

\author{
UNIVERSITY OF SOUTHERN CALIFORNIA \\ STANFORD UNIVERSITY \\ UNIVERSITY OF HAWAII \\ UNIVERSITY OF TOKYO \\ UNIVERSITY OF UTAH \\ WASHINGTON STATE UNIVERSITY \\ UNIVERSITY OF WASHINGTON
}

The Supporting Institutions listed above contribute to the cost of publication of this Journal, but they are not owners or publishers and have no responsibility for its content or policies.

Mathematical papers intended for publication in the Pacific Journal of Mathematics should be in typed form or offset-reproduced, (not dittoed), double spaced with large margins. Please do not use built up fractions in the text of the manuscript. However, you may use them in the displayed equations. Underline Greek letters in red, German in green, and script in blue. The first paragraph or two must be capable of being used separately as a synopsis of the entire paper. Please propose a heading for the odd numbered pages of less than 35 characters. Manuscripts, in triplicate, may be sent to any one of the editors. Please classify according to the scheme of Math. Reviews, Index to Vol. 39. Supply name and address of author to whom proofs should be sent. All other communications should be addressed to the managing editor, or Elaine Barth, University of California, Los Angeles, California, 90024.

50 reprints to each author are provided free for each article, only if page charges have been substantially paid. Additional copies may be obtained at cost in multiples of 50 .

The Pacific Journal of Mathematics is issued monthly as of January 1966. Regular subscription rate: $\$ 84.00$ a year (6 Vols., 12 issues). Special rato: $\$ 42.00$ a year to individual members of supporting institutions.

Subscriptions, orders for numbers issued in the last three calendar years, and changes of address shoud be sent to Pacific Journal of Mathematics, P.O. Box 969, Carmel Valley, CA 93924, U.S.A Old back numbers obtainable from Kraus Periodicals Co., Route 100, Millwood, NY 10546.

PUBLISHED BY PACIFIC JOURNAL OF MATHEMATICS, A NON-PROFIT CORPORATION

Printed at Kokusai Bunken Insatsusha (International Academic Printing Co., Ltd.). 8-8, 3-chome, Takadanobaba, Shinjuku-ku, Tokyo 160, Japan. 


\section{Pacific Journal of Mathematics \\ Vol. 88, No. $2 \quad$ April, 1980}

Reinhold Böhme, Stefan Hildebrandt and Engelbert Tausch, The two-dimensional analogue of the catenary ................. 247

Jean Ellen Taylor, Nonexistence of F-minimizing embedded disks ........ 279

Claus Gerhardt, A free boundary value problem for capillary surfaces ..... 285

Enrico Giusti, Generalized solutions for the mean curvature equation . . . . . 297

Jin-Tzu Chen, On the existence of capillary free surfaces in the absence of gravity.................................... 323

Leon M. Simon, Regularity of capillary surfaces over domains with corners.......................................... 363

Nicholas Jacob Korevaar, On the behavior of a capillary surface at a re-entrant corner.................................... 379

Henry Wente, The symmetry of sessile and pendent drops ............ 387

E. Gonzalez, Umberto Massari and I. Tamanini, Existence and regularity for the problem of a pendent liquid drop ...................... 399

Henry Wente, The stability of the axially symmetric pendent drop ........ 421

David Siegel, Height estimates for capillary surfaces . . . . . . . . . . . . 471

Bruce Edward Turkington, Height estimates for exterior problems of capillarity type ................................ 517

Robert Finn, The sessile liquid drop. I. Symmetric case .............. 541 